\title{
Growth in Beagles: Changes in Body Weight, Plasma Volume, and Venous Hematocrit
}

\author{
R. A. Huggins ${ }^{[27]}$, S. Deavers, and E. L. Smith \\ Department of Physiology, Baylor College of Medicine and The University of Texas Dental Branch, \\ Texas Medical Center, Houston, Texas, USA
}

\begin{abstract}
Extract
Body weight, plasma volume, and venous hematocrit of 12- to 18-hr-old beagles were $0.239 \pm 0.009 \mathrm{~kg}, 52.5 \pm 1.14 \mathrm{ml} / \mathrm{kg}$, and $48.7 \pm 1.72 \%$, respectively. Over the next $24 \mathrm{hr}$ total plasma volume increased by $31 \%$ and body weight by only $8 \%$. During the 1 -year period after birth the plasma volume (milliliters per kilogram) changed abruptly four times, and each change was followed by stable periods of varying length. The plasma volume decreased significantly between weeks 1 and 2, weeks 6 and 7 , and months 3 and 4; and, finally, it increased significantly between months 5 and 6 . The venous hematocrit declined during the first 6 weeks of life, then gradually increased up to month 6 . Body weight, plasma volume, and venous hematocrit did not change significantly from months $6-12$. Plasma volume (milliliters per kilogram) for 6- to 12 -month-old beagles was 44.3 , significantly less than that of the newborn.
\end{abstract}

\section{Speculation}

These data suggest the need to explore mechanisms concerned with the several abrupt changes in the plasma volume that occurred during growth of the beagle and in the mechanisms involved in the marked increase in plasma volume with no reduction in venous hematocrit on day 1 .

\section{Introduction}

The blood volume of the newborn of a number of species of animals, expressed in milliliters per kilogram body weight (blood volume ratio), is significantly larger than that of the adult $[5,11,12,16]$, although at least one animal, the pig, appears to be an exception to this generalization [17]. It is impossible to decide, because of the contradictory data in the literature, whether or not there is a similar decrease in blood volume with growth in the human $[4,19,21]$.

Even if blood volume in milliliters per kilogram body weight decreases during growth, the plasma volume (milliliters per kilogram, hereafter called plasma volume) does not necessarily decrease, or, if a decrease occurs, it may not parallel the change in blood volume. Mott's data on rabbits [16] illustrate the latter possibility: although the mean plasma volume was stable from birth until day 31 of age, blood volume ratio decreased significantly. In the adult rabbit, however, the plasma volume was less than that of the newborn.

Despite a considerable quantity of data on the plasma volume of humans at different ages, it is difficult to decide whether the plasma volume of the adult is significantly less than that of the newborn and young $[4,6,19,20]$. Thus, from the data available in the literature it was impossible to make firm conclusions on the relation between age, body weight, plasma volume, and hematocrit from birth to maturity for any single species. Further, it seemed probable that if adequate data were collected, significant changes in 
one or more of these variables with growth might be revealed that were not evident when only a few data were collected and fitted to a smoothed curve. Therefore, data for these variables were collected on beagles from birth to 12 months of age.

\section{Materials and Methods}

A breeding colony of registered beagles consisting of 40 females and 3 males was established and maintained at the Wynne Unit of the Texas Department of Corrections, Huntsville, Texas, about 75 miles from Houston. Huntsville lies outside the Gulf Coast area where heartworm infestation is a serious problem. The colony was under the supervision of a veterinarian.

The gestation period of the beagle is 62 days, and with the approach of whelping time the bitch was placed in the whelping room and a 24-hr watch was maintained. After whelping, the bitch and her puppies were kept in a large cage for 5-6 weeks, then transferred to a partially covered run. At about week 4 of age the puppies' diet was supplemented four times a day with a combination of puppy meal [24], milk, and some horse meat. The puppies were weaned around week 7 of age and were fed an adult diet of dog chow ad libitum [24].

The pups were immunized against distemper and hepatitis at week 2 of age and at regularly scheduled intervals thereafter.

With the exception of 0 day (first $24 \mathrm{hr}$ after birth) and 1-day-old pups, where only $1 \mathrm{mg}$ morphine was

Table I. Plasma volume, hematocrit, and body weight of beagles from 0 to 2 days after birth

\begin{tabular}{|c|c|c|c|}
\hline & \multicolumn{3}{|c|}{ Days after birth } \\
\hline & $0^{1}$ & 1 & 2 \\
\hline Plasma volume, $\mathrm{ml} / \mathrm{kg}$ & $\begin{array}{c}52.5 \underset{(12)^{3}}{ \pm} \\
\left(1.14^{2}\right.\end{array}$ & $\begin{array}{c}63.5 \\
\pm 3.10 \\
(10)\end{array}$ & $\begin{array}{c}61.7 \\
\pm 2.74 \\
(11)\end{array}$ \\
\hline$P$ values & & $<0.005^{4}$ & \\
\hline Venous hematocrit, $\%$ & $\begin{array}{c}48.7 \pm 1.72 \\
(12)\end{array}$ & $\begin{array}{c}51.4 \\
\pm 1.93 \\
(9)\end{array}$ & $\begin{array}{c}47.2 \\
\pm 1.72 \\
(11)\end{array}$ \\
\hline Body wt, kg & $\begin{array}{c}0.239 \pm 0.009 \\
(12)\end{array}$ & $\begin{aligned} & 0.258 \\
+ & 0.019 \\
& (14)\end{aligned}$ & $\begin{aligned} & 0.274 \\
\pm & 0.012 \\
& (11)\end{aligned}$ \\
\hline
\end{tabular}

\footnotetext{
1 From 2 to $18 \mathrm{hr}$ after birth.

${ }^{2}$ Means $\pm \mathrm{SE}$.

${ }^{3}$ Number in parentheses indicates number of cases.

4 The standard $t$ test was used to compare means.
}

given to sedate the animals, all animals were anesthetized with a combination of morphine sulfate given subcutaneously and sodium pentobarbital administered intraperitoneally or intravenously. The dosage of morphine used in the puppies ranged from 2 to 5 $\mathrm{mg} / \mathrm{kg}$ up to the age of 3 months. Sodium pentobarbital $(7.5-15 \mathrm{mg} / \mathrm{kg})$ was injected intraperitoneally up to 3 months of age. Dogs older than 3 months were given $10 \mathrm{mg} / \mathrm{kg}$ morphine subcutaneously and 15 $\mathrm{mg} / \mathrm{kg}$ sodium pentobarbital intravenously.

If the dogs were under 9 weeks old, a plastic tube fitted with a 18- to 20-gauge needle was inserted into the external jugular vein for injection of ${ }^{131}$ I-tagged albumin and for withdrawal of blood. At the end of the experiment the catheter was removed, the jugular ligated, and the skin incision closed. The pups were given penicillin to prevent wound infection and returned to their mother or to the run. For dogs over 9 weeks old the tagged albumin was injected directly into the jugular vein and blood samples were drawn from the jugular by vena puncture. Measurements were repeated on many of the dogs when they were older; however, a sufficient amount of time elapsed between experiments so that no radioactivity from the previous injection was detected in the plasma.

Table I presents data for 0-2 days; pups from at least three different litters were used to calculate the mean values for each day. The number of litters used in compiling the means for Figure $I$ and Tables $I$ and II in most instances was greater than three. The decision to group the data by the age of the pups into a format of weeks and then months was arbitrary. None of the puppies used in these experiments was premature.

The experimental techniques used are standard in this laboratory and have been reported in detail elsewhere [13]. The method using ${ }^{131}$ I-tagged albumin was employed to measure plasma volume, and in every instance plasma volume was calculated from a dilution curve with at least three time-concentration points plotted on semilogarithmic paper and extrapolated back to the time of injection $(0 \mathrm{~min})$. Blood samples $(1.5 \mathrm{ml})$ were drawn into heparinized syringes 10,20 , 30 , and, in pups older than $24 \mathrm{hr}, 60 \mathrm{~min}$ after injection of the tag. Hematocrits were determined by the microhematocrit method on all blood samples.

\section{Results}

The mean plasma volume from 2-18 hr (0 day in Table I) after birth was 52.5 , but during the succeeding $24 \mathrm{hr}$ (day 1 of Table I) this ratio increased significantly 


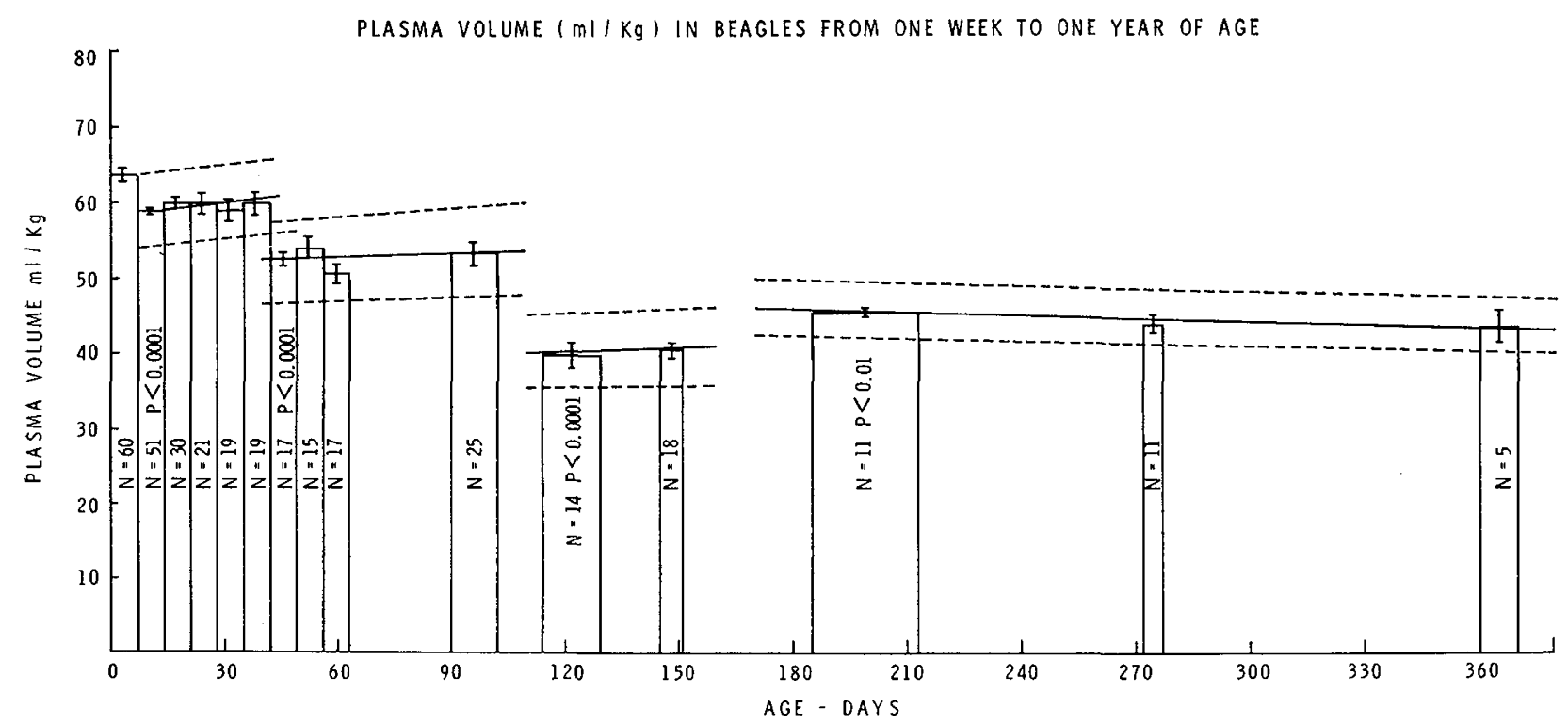

Fig. 1. Width of each column gives the range in the age of pups (days) for a particular mean plasma volume. Vertical bars show $1 \mathrm{SE}$ of the mean. N : number of dogs. The difference between means was calculated by Student's $t$ test and a $P$ value of less than 0.01 was considered significant. The line of best fit was calculated for each plateau by the method of least squares using the general formula, $y=a+$ $b x$, where $y=$ plasma volume, $\mathrm{ml} / \mathrm{kg} ; a=$ intercept constant; $b=$ slope constant; and $x=$ age in days. The formulas for the lines were as follows: $8-42$ days: $y=58.3+0.0585 x ; 43-102$ days: $y=51.89+0.0121 x$; 114-151 days: $y=38.4+0.0136 x$; and 185-365 days: $y=48.5+(-0.0158) x$. The slope of the lines did not differ significantly from 0 . The broken lines represent $\pm 1 \mathrm{SE}$ of the line.

by $11(P<0.005)$. There was no difference in plasma volume between pups 2- and those 18-hrold.

In Figure 1 the mean plasma volume was plotted on a weekly basis through the first 9 weeks after birth, on a monthly basis from month 3 through month 6 , and finally, for months 9 and 12. For week 1 (not including 0 day), the plasma volume was 63.8 with a decrease for week 2 to 59.9 , a difference statistically significant at the $0.1 \%$ level. The mean plasma volume for each week from weeks 2 through 6 did not differ significantly from each other, ranging from a minimum of 58.9 for week 2 to a maximum of 60.0 for week 6 , and averaging 59.5 for the entire period.

The plasma volume ratio decreased significantly by 8 $(P<0.0001)$ for week 7 , and plateaued at 52.7 from week 7 through week 12. The maximum plasma volume during this time was 53.9 for week 8 and the minimum was 50.6 for week 9 .

The next significant decrease in mean plasma volume amounted to $13.3(P<0.0001)$ and occurred between months 3 and 4 . It was 39.7 for month 4 and remained at this level through month 5 (40.6). The final plateau began in month 6 with an increase over month 5 to $45.5(P<0.01)$ and continued through month 12. The average plasma volume for the last 6 months was $44.3 \pm 3.79 \mathrm{ml} / \mathrm{kg}$.
Mean values for total plasma volume, body weight, and venous hematocrit at different ages are given in Table II. Only at four time periods during year 1 did body weight and plasma volume increase disproportionately between weeks 1 and 2 , between weeks 6

Table II. Changes in body weight, plasma volume, and venous hematocrit

\begin{tabular}{cccc}
\hline Age & $\begin{array}{c}\text { Body wt, } \\
\mathrm{kg}\end{array}$ & $\begin{array}{c}\text { Plasma volume, } \\
\mathrm{ml}\end{array}$ & $\begin{array}{c}\text { Venous hematocrit, } \\
\%\end{array}$ \\
\hline Week & & & \\
$1(60)^{1}$ & $0.34 \pm 0.01^{2}$ & $21.6 \pm 0.7$ & $40.7 \pm 1.03$ \\
$2(51)$ & $0.58 \pm 0.03$ & $34.7 \pm 1.4$ & $33.7 \pm 0.73$ \\
$3(30)$ & $0.89 \pm 0.04$ & $53.5 \pm 2.4$ & $29.0 \pm 0.53$ \\
$4(21)$ & $1.14 \pm 0.05$ & $68.0 \pm 3.2$ & $27.6 \pm 0.80$ \\
$5(19)$ & $1.66 \pm 0.07$ & $96.2 \pm 2.8$ & $25.5 \pm 1.29$ \\
$6(19)$ & $1.87 \pm 0.09$ & $111.8 \pm 5.7$ & $23.8 \pm 0.53$ \\
$7(17)$ & $2.43 \pm 0.07$ & $128.4 \pm 5.1$ & $27.6 \pm 1.28$ \\
$8(15)$ & $2.69 \pm 0.16$ & $145.9 \pm 6.0$ & $28.6 \pm 0.91$ \\
$9(17)$ & $3.15 \pm 0.15$ & $173.7 \pm 15.0$ & $32.3 \pm 0.51$ \\
Month & & & \\
$3(25)$ & $5.19 \pm 0.17$ & $273.2 \pm 9.0$ & $34.1 \pm 0.78$ \\
$4(14)$ & $6.80 \pm 0.21$ & $269.1 \pm 13.5$ & $40.9 \pm 0.96$ \\
$5(18)$ & $7.85 \pm 0.28$ & $318.2 \pm 12.5$ & $42.1 \pm 0.75$ \\
$6(11)$ & $11.00 \pm 0.39$ & $499.0 \pm 18.0$ & $48.7 \pm 2.05$ \\
$9(11)$ & $10.6 \pm 0.58$ & $462.5 \pm 24.5$ & $43.4 \pm 1.16$ \\
$12(5)$ & $11.5 \pm 0.64$ & $497.4 \pm 35.5$ & $46.9 \pm 2.00$ \\
\hline
\end{tabular}

${ }_{1}$ Number in parentheses indicates number of determinations. 2 Mean \pm se. 
and 7 , between months 3 and 4, and between months 5 and 6.

The venous hematocrit increased from 48.7 in beagles 2- to 18 -hr old to $51.4 \%$ on day 1 , but the difference was not statistically significant (Table I). The mean venous hematocrit from day 1 through day 7 was $40.7 \%$ and declined continuously through week 6 when it reached $23.8 \%$ (Table II). From week 7 through month 6 there was a steady upward trend in the venous hematocrit, reaching the highest mean value of $48.7 \%$ in month 6 . The hematocrit then decreased to $43.4 \%$ in month 9 but increased to $46.9 \%$ in month 12; however, these changes were not statistically significant.

It was found that the plasma volume for each animal was very close to the mean of the appropriate age group (Fig. 1), and the same breaks were seen during the growth period for an individual dog that occurred with the pooled data.

\section{Discussion}

While the period immediately after birth can be regarded as a period of transition for the newborn, there was no evidence of instability of the plasma volume from 2 to $18 \mathrm{hr}$ after birth. During the next $24 \mathrm{hr}$, however, as a result of an unknown stimulus, $11 \mathrm{ml} / \mathrm{kg}$ of fluid entered the circulation. Although the plasma volume increased, the venous hematocrit, instead of decreasing as expected, increased on day 1, but not significantly. Consequently, with an increase in plasma volume and essentially no change in venous hematocrit, either erythrocytes must have been added to the circulation or cells were redistributed to the large blood vessels.

The finding that the hematocrit was maintained or increased during the first $48 \mathrm{hr}$ after birth in the dog was contrary to observations reported by McCance and Widdowson [15] and Ramirez et al. [17] on the pig that the venous hematocrit fell significantly during the $24 \mathrm{hr}$ after birth. The decrease was a consequence of an increased plasma volume caused by an increased concentration of plasma proteins in the circulation, the added protein coming from colostrum in the gut [15]. Although the venous hematocrit of the puppies did not change significantly during the first $48 \mathrm{hr}$ after birth, there was a significant increase in plasma volume similar to that observed in the pig. The increased plasma volume in the pup on day 1 was maintained through the next 5 days, a finding similar to that of Ramirez et al. [17] in the pig.

In the human, Low et al. [14] and Usher et al. [23] reported an increase in plasma volume during the first $24 \mathrm{hr}$ after birth and a small decrease in venous hematocrit, and Sisson and Whalen [20] measured an increase in both plasma volume and hematocrit within 3-5 hr after birth. Other investigators, however, found no change in plasma volume in $50 \%$ of a series of newborns studied in the first $24 \mathrm{hr}$ [14], in 1-3 days [9], or a significant decrease within $2 \mathrm{hr}$ after birth [22]. One of the complicating factors which might account for some of the differences between these data was the time elapsing between delivery and clamping of the cord $[9,23]$.

For many species of animals, including the rat $[2,5$, $10]$, rabbit [3,16], lamb [12], pig [17], and guinea pig [5], the plasma volume, when expressed in milliliters per kilogram body weight, decreased during growth. The same phenomenon was observed in the beagle, the mean plasma volume being 62 for week 1 after birth, decreasing to 43.5 at 1 year of age.

It is difficult to know from published data on the human whether there was a decreasing plasma volume over the growth period as seen in other species. For example, Brines et al. [4] reported an increased plasma volume between the ages of 2-17 years; Friis Hansen [10], a small increase from the newborn to the adult; and Russell [19], no change in plasma volume in children from 3-13 years of age. However, since the plasma volume, when expressed per unit of body weight, decreases during growth in a number of mammalian species, it would seem probable, if sufficient data were available, that the same trend would occur in the human.

The final plasma volume was reached by a series of changes which were characterized by their relative abruptness, and each change was followed by a period of varying length in which the plasma volume was stable. The changes in plasma volumes were the result of a greater increase in body weight than in plasma volume, with the exception of the change that occurred between months 5 and 6 ; for example, between weeks 6 and 7 there was a $30 \%$ gain in weight but only a $15 \%$ increase in plasma volume.

The primary physiological mechanisms involved in the divergence between rate of increase of plasma volume and body weight at various times during growth of the dog are not clear at present. Several of the changes in plasma volume, however, coincide approximately with physiological activity known to have an influence on development and growth. The break that occurs between weeks 6 and 7 coincides with weaning and suggests the possibility that the change in the pup's 
diet may be related to the greater increase in body weight compared with that of plasma volume found at this time. A relation between weaning and erythrocyte volume was suggested by Anderson and Gee [1], who measured, among other blood elements, the hematocrit of beagles from birth to 1 year of age, and found that from birth until the pups were 28-30 days old there was a steady decline. At about 30 days the hematocrit began to increase, and they noted that the increase coincided with the time the pups' diet was supplemented with solid food. The venous hematocrit of our puppies increased for the first time in week 7 and coincided with the weaning period between weeks 6 and 7 .

There was another significant decrease in plasma volume between months 3 and 4 with plasma volume being stable for months 4 and 5 . The mean body weight of the 4-month-old beagles increased by $31 \%$, but the plasma volume decreased by $1 \%$. Also, at month 4 there was a difference between the body weight of males and females which became statistically significant at month 5. It seems a reasonable assumption that one or more of the sex hormones was involved with the development of the sex differences in body weight, but apparently there was no influence on the plasma volume at this time.

The previous abrupt changes in the plasma volume were associated with a greater increase in body weight than in plasma volume, but for the break between months 5 and 6 the opposite was true: the plasma volume increased by $59 \%$ and the body weight by only $40 \%$. Since there was no further significant change in plasma volume from months 6 through 12, the dogs can be considered to have reached their adult plasma volume level at 6 months of age. During the period in which the plasma volume reached adult values and was finally established, there must have been increasing endocrine activity because, in addition to the significant weight difference that developed between the sexes in month 5 , by month 8 a number of the females were in heat. These relations suggest that there may be hormonal involvement in the regulation of the adult plasma volume.

The fall in venous hematocrit during the early part of the growth period seen in the beagle has been reported for other species-rat [5, 11], rabbit [16], pig [17], and human $[14,21]$-and appears to be a general phenomenon accompanying growth. In the beagle the hematocrit decreased steadily through the first 6 weeks, then began to increase gradually, reaching the adult level at month 6 . During the period of declining hematocrit there was no significant change in plasma volume in milliliters per kilogram; therefore, there was either a reduction in the total erythrocyte volume or the production of erythrocytes did not parallel the increase in total plasma volume. In the rat, according to Garcia [11], despite a decrease in hematocrit, erythropoiesis increased.

Robinson and Ziegler [18], using 202 beagles 6-12 months old, have published normal values for a number of variables which permit comparison of pertinent data from our colony. They reported a mean hematocrit of $43.5 \%$; our dogs of comparable age had venous hematocrits of $46.2 \%$. The combined data permit the conclusion that plasma volume and venous hematocrit of the beagle were stabilized from months 6-12 after birth and that the adult values for these variables were achieved in month 6 .

The plasma volume of adult beagles (12 months) was lower than that of mongrels, $44.5 \pm 1.43$ and $50.2 \pm 1.11 \mathrm{ml} / \mathrm{kg}$, respectively [7]. This finding agrees with data of other investigators [8]. No significant difference was found between the venous hematocrits of our beagles and mongrels, although others have reported a higher erythrocyte percentage for beagles $[1,8]$.

Expressing plasma volume per unit of body weight, as we have done, disregards the fact that in other animals body solids and fat are not added during growth in the same proportions that exist at birth, and the beagle is probably not an exception to the generalization. Consequently, data are needed which will permit comparisons of the changes seen in plasma volume with measurements of total protein, fat-free body weight, total body water, and extracellular fluid. These data are in the process of being accumulated.

\section{Summary}

During day 2 of life, there was a shift of fluid into the vascular system of the beagles while the venous hematocrit remained unchanged. The mean plasma volume was higher in 1-week-old than in 1-year-old beagles. The plasma volume seen in adult beagles was reached by a series of abrupt changes at different ages, each change followed by a period during which plasma volume was stable. Most of these changes were the result of a greater change in body weight than in total plasma volume. The venous hematocrit decreased steadily through the first 6 weeks after birth; then it began to increase gradually, reaching the adult level at 6 months of age.

\section{References and Notes}

1. Andersen, A. C., and GeE, W.: Normal blood values in the beagle. Vet. Med., 53: 135 (1958). 
2. Belcher, E. H., and Harriss, E. B.: Studies of plasma volume, red cell volume and total blood volume in young growing rats. J. Physiol., 139: 64 (1957).

3. BoccI, V., AND VIrI, A.: Plasma and blood volumes estimated by the serum ${ }^{131}$ I-proteins method in normal rabbits of varying body weight. Quart. J. Exp. Physiol., 51: 27 (1966).

4. Brines, J. K., Gibson, J. G., II, ANd Kunkel, P.: The blood volume in normal infants and children. J. Pediat., 18: 447 (1941).

5. Constable, B. J.: Changes in blood volume and blood picture during the life of the rat and guinea-pig from birth to maturity. J. Physiol., 167: 229 (1963).

6. Darrow, D. C., Soule, H. C., ANd Buckman, T. E.: Blood volume in normal infants and children. J. Clin. Invest., 5: 243 (1928).

7. Deavers, S., Smith, E. L., and Hugggins, R. A.: Control circulatory values of morphine-pentobarbitalized dogs. Amer. J. Physiol., 199: 797 (1960).

8. Dellenback, R. J., Usami S., Chien, S., and Gregersen, M. I.: Effects of splenectomy on blood picture, blood volume, and plasma proteins in beagles. Amer. J. Physiol., 217: 891 (1969).

9. DeMarsh, Q. B., Windle, W. F., AND Alt, H. L.: Blood volume of newborn infant in relation to early and late clamping of umbilical cord. Amer. J. Dis. Children, 63: 1123 (1942).

10. Fris-Hansen, B.: Body water compartments in children: changes during growth and related changes in body composition. Pediatrics, 28: 169 (1961).

11. Garcia, J. F.: Changes in blood, plasma and red cell volume in the male rat, as a function of age. Amer. J. Physiol., 190: 19 (1957).

12. Gotsev, T.: The blood volume in lambs. J. Physiol., 94: 539 (1939).

13. Huggins, R. A., Smith, E. L., and Deavers, S.: Volume distribution of Evans blue dye and iodinated albumin in the dog. Amer. J. Physiol., 205: 351 (1963).

14. Low, J. A., Kerr, N. D., And Cochan, A. R.: Plasma and blood volume of the normal newborn infant and patterns of adjustment in initial 24 hours of the neonatal period. Amer. J. Obstet. Gynecol., 86: 886 (1963).
15. McCance, R. A., And Widdowson, E. M.: The effect of colostrum on the composition and volume of the plasma of newborn piglets. J. Physiol., 145: 547 (1959).

16. Motr, J. C.: Haemorrhage as a test of the function of the cardiovascular system in rabbits of different ages. J. Physiol., 181: 728 (1965).

17. Ramirez, G. G., Miller, E. R., Ullrey, D. E., AND Hoefer, J. A.: Swine hematology from birth to maturity. III. Blood volume of the nursing pig. J. Anim. Sci., 22: 1068 (1963).

18. Robinson, F. R., AND ZiEgLer, R. F.: Clinical laboratory values of beagle dogs. Lab. Anim. Care, 18: 39 (1968).

19. RusselL, S. J. M.: Blood volume studies in healthy children. Arch. Dis. Childhood, 24: 88 (1949).

20. Sisson, T. R. C., and Whalen, L. E.: The blood volume of infants. III. Alterations in the first hours after birth. J. Pediat., 56: 43 (1960).

21. Sisson, T. R. C., Lund, C. J., Whalen, L. E., and Telek, A.: The blood volume of infants. I. The full-term infant in the first year of life. J. Pediat., 55: 163 (1959).

22. Steele, M. W.: Plasma volume changes in the neonate. Amer. J. Dis. Children, 103: 10 (1962).

23. Usher, R., SHePHARD, M., AND Lind, J.: The blood volume of the newborn infant and placental transfusion. Acta Paediat., 52: 497 (1963).

24. Purina, Ralston-Purina Company, St. Louis, Mo.

25. We acknowledge the technical help given us by Mrs. Dorothy Barber and Mr. William Sears. Also, it is a pleasure to thank the Texas Department of Correction for permitting and assisting us to maintain our dog colony at Wynne Unit at Huntsville, and particularly Sergeant Percy Crooks. Finally, without the thoughtfulness and constant help of Mr. Edward Crowell the completion of this study would have taken much longer.

26. Supported by National Heart Institute Grants nos. HE-11395 and HE-05435.

27. Requests for reprints should be addressed to: R. A. Huggins, Ph.D., Department of Physiology, Baylor College of Medicine, 1200 Moursund Avenue, Houston, Texas 77025 (USA).

28. Accepted for publication July I, 1970. 